\title{
Electrochemical Behaviors of Chlorophenol Aqueous Solutions at Boron- Doped Diamond Electrode
}

\author{
Fengbin Liu*, Guangping He, Ming Zhao, Min Qu and Lingjiao Huang \\ College of Mechanical and Electrical Engineering, North China University of Technology, Beijing, 100144, China
}

\begin{abstract}
The electrochemical behaviors of different chlorophenols at boron-doped diamond thin film electrode were investigated. Four chlorophenols, the 2-chlorophenol (2-CP), 2,4-dichlorophenol (2,4-DCP), 2,4,6-trichlorophenol (2,4,6TCP) and pentachlorophenol (PCP), with various number of chlorine atoms in the benzene rings, were studied by using cyclic voltammetry at different scan rates over the potential range of $-1 \mathrm{~V}$ to $2.5 \mathrm{~V}$ ( $v S \mathrm{MSE}$ ). The results indicated that the reactions of the 2-CP, 2,4-DCP and 2,4,6-TCP at the diamond electrode are irreversible and controlled by diffusion, and the irreversible trend increases with the decrease of the chlorine atom number in the benzene ring. However, the activity of the boron-doped diamond film electrode does not depend on the number of the chlorine atom. Different from the three chlorophenols, fouling of the electrode occurs in PCP solutions. The possible electro-oxidation mechanisms are discussed for different chlorophenols.
\end{abstract}

Keywords: Boron-doped diamond film, chlorophenol oxidation, cyclic voltammetry, diffusion control.

\section{INTRODUCTION}

The chlorophenols (CPs) are the key intermediates by the reaction of some organic matters with chlorocarbons [1]. They are the main hazardous pollutants in the wastewater of the herbicides and the insecticides. Moreover, their environmental persistence and toxicity are harmful to many lives [2,3]. Though the chlorophenols are hard to be degraded and some traditional treatment methods are not very effective $[4,5]$, the removal of them from the water attracts many researchers. Among all the present treatment methods, electrochemical treatment is a promising technique.

Several research groups have reported their research results of the electrochemical oxidation of different organic pollutants at different electrodes. Ureta-Zañartu [6] investigated the electro-oxidation of several chlorophenols at a glassy carbon electrode and suggested that for the same number of chlorine atoms, the ortho isomer is oxidized at a lower potential than the para isomer. Montilla [7] studied the electrochemical oxidation of the benzoic acids (BA) using boron-doped diamond (BDD) electrodes by cyclic voltammetry and reported that the BA is oxidized with the deactivation of the electrode due to the fouling. Gattrell [8] and Iniesta [9] reported that phenol electro-oxidation produces electrode fouling and tars form on the electrode by electropolymerization, Cañizares [10] studied the electrochemical oxidation of several chlorophenols aqueous waste by boron-doped diamond electrode and found that the organic pollutants are completely converted into carbon dioxide and volatile chlorinated organic compounds are achieved. However, to our knowledge, few reports refer to

*Address correspondence to this author at the College of Mechanical and Electrical Engineering, North China University of Technology, Beijing, 100144, China; Tel: +86-10-88802892; Fax: +86-10-88803161;

E-mails: fbliu@ncut.edu.cn, fbliu@mail.tsinghua.edu.cn the effects of the chlorine atom number of the chlorophenols on their electrochemical behaviors at boron-doped diamond film electrode.

In this paper, the electrochemical behaviors of several chlorophenols were studied with cyclic voltammetry (CV) at boron-doped diamond electrode. To determine the effect of the chlorine atom number in the aromatic ring on the reactivity, 2-chlorophenol (2-CP), 2,4-dichlorophenol (2,4DCP), 2,4,6-trichlorophenol (2,4,6-TCP) and pentachlorophenol (PCP) solutions were adopted as the samples of the electrolyte. The possible mechanisms of chlorophenols degradation are discussed.

\section{EXPERIMENTAL}

The boron-doped diamond films were deposited onto low-resistivity silicon (p-type) substrates from a hot-filament activated methane hydrogen gas mixture with the pressure of 50Torr in a chemical vapor deposition (CVD) system. The filament temperature was $2500^{\circ} \mathrm{C}$, and that of substrates was $830^{\circ} \mathrm{C}$. Boron doping of diamond film was achieved by adding trimethyl borate to the reaction mixture in the course of their growth (B/C ratio: $3 \mathrm{ppm})$. The mixture flowed at the rate of $5 \mathrm{~L} / \mathrm{min}$, and the growth rate was $0.24 \mu \mathrm{m} / \mathrm{h}$. A continuous film of diamond was obtained after 15 hours of growth. The film resistance was in the range of $1-10 \Omega$, which was measured in a solid-state arrangement.

The surface morphology of the grown diamond film was investigated with the scanning probe microscopy (SPM, SPA-300HV). The Raman spectra of five different measuring positions on the grown diamond film were recorded by using a laser beam of $514 \mathrm{~nm}$ wavelength (Renishaw RM1000). To investigate the electrochemical properties of the deposited boron-doped diamond film, its electrochemical window was measured by using cyclic voltammogram over the potential range of $-1 \mathrm{~V}$ to $2.5 \mathrm{~V}$ ( $v S$ MSE) with the scan rate of $100 \mathrm{mV} / \mathrm{s}$ in $1 \mathrm{mM} / \mathrm{L} \mathrm{Na} \mathrm{SO}_{4}$ solutions. For comparison, the electrochemical windows of 
the Pt and active coating $\mathrm{Ti}$ (ACT) electrodes were also investigated under the same experimental conditions.

The chlorophenol aqueous solutions were freshly prepared using reagent grade chemical in deionized water. The mixture of $0.5 \mathrm{M} \mathrm{Na}_{2} \mathrm{SO}_{4}$ and $10 \mathrm{mM} \mathrm{H}_{2} \mathrm{SO}_{4}(\mathrm{pH}=2.2)$ was used as buffer solution. A pH of 2.2 was preferentially used in order to avoid the protonation of the chlorophenols that occurs at very low $\mathrm{pH}$ values [11]. The concentrations of the chlorophenols in the solutions were all adopted as $1 \mathrm{mM} / \mathrm{L}$. All the electrochemical experiments were carried out at room temperature. A single compartment electrochemical cell with three electrodes (BDD plates of $1 \mathrm{~cm}^{2}$ of geometric area as test electrode, platinum wire as counter electrode, $\mathrm{Hg} / \mathrm{Hg}_{2} \mathrm{SO}_{4} / \mathrm{KCl}$ (sat) as reference electrode) was used in this experimental study. A potentiostat (EG\&G Model 273) was used to obtain the cyclic voltammogram over a potential range of $-1 \mathrm{~V}$ to $2.5 \mathrm{~V}$ (vs MSE) and the scan rates were 5, 10, 20, 50, 100, 150, $200 \mathrm{mV} / \mathrm{s}$. Suitable software was used to control the experiments and acquire experiment data. The solution was not purged during electrochemical measurements. After each measurement, the BDD electrode was cleaned by acetone and deionized water.

\section{RESULTS AND DISCUSSION}

Fig. (1) shows the morphology of boron-doped diamond grown on the silicon substrate. The morphology of the grown diamond film is well faceted and consistent with nano-size crystallites (about $200 \mathrm{~nm}-600 \mathrm{~nm}$ ). Its surface roughness is $47.52 \mathrm{~nm}$ (rms), which is measured by using SPM.

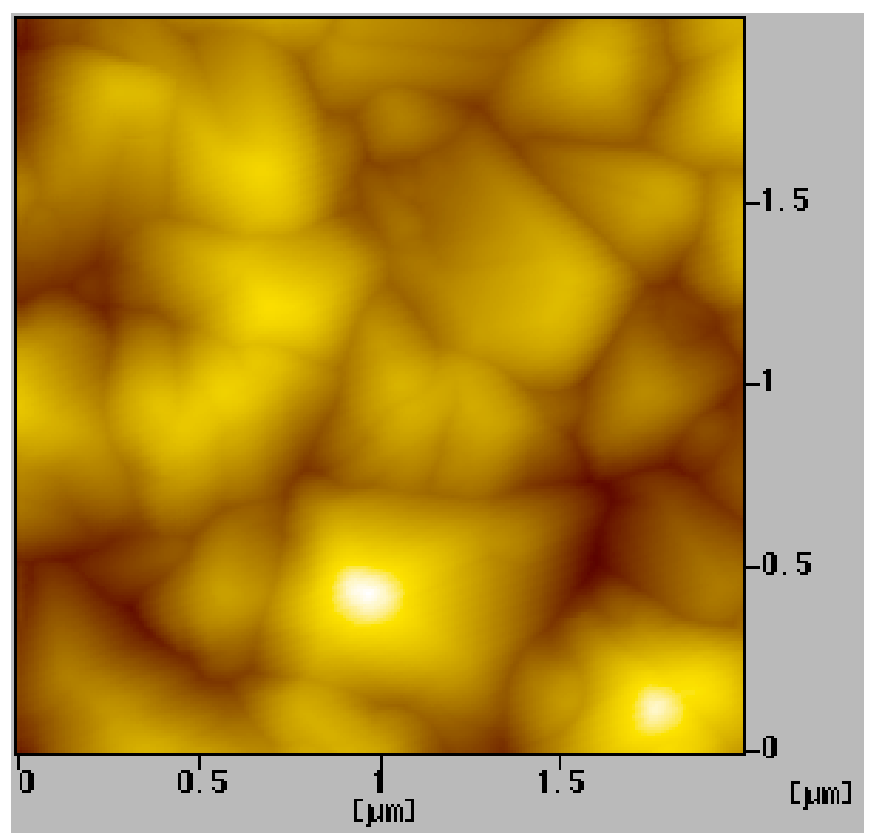

Fig. (1). The SPM image of the BDD film.

For the grown diamond film, there is only a small admixture of non-diamond carbon, as revealed by taking their Raman spectra (Fig. 2). The spectra exhibit a well pronounced $1331.2 \mathrm{~cm}^{-1}$ peak which is due to the first order scattering by diamond. The full width at the half-maximum of the $1331.2 \mathrm{~cm}^{-1}$ peak is $14 \mathrm{~cm}^{-1}$. The peak height obviously exceeds that at $1540 \mathrm{~cm}^{-1}$, which is due to the non-diamond carbon. In addition, there exist obvious peaks at $920 \mathrm{~cm}^{-1}$ and $1200 \mathrm{~cm}^{-1}$, respectively, where the features of the second order silicon and nano-crystalline diamond phase locate [12]. Notes the Raman spectra of the five measuring positions at the grown diamond film, the phase structures are similar to each other. It followed that the grown diamond film is of high quality.

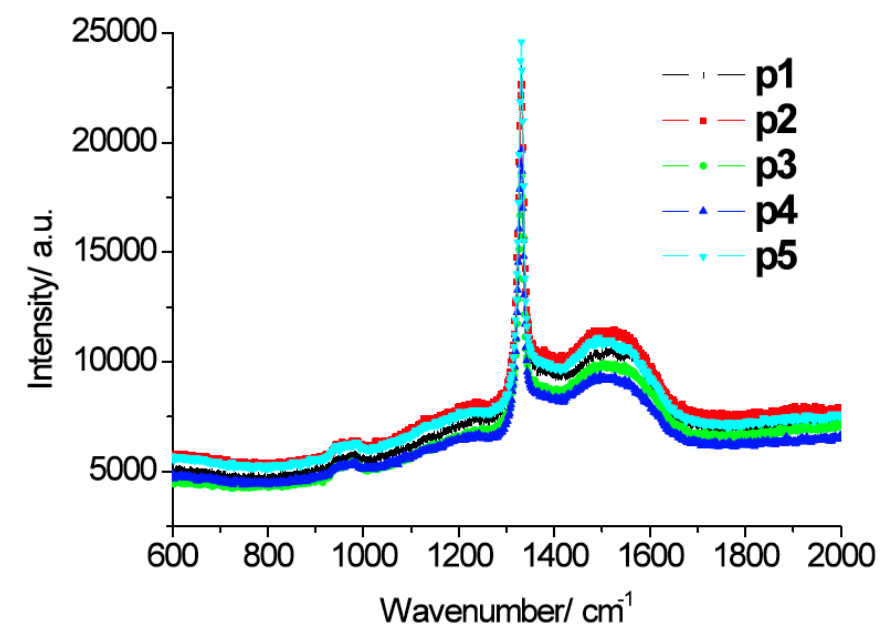

Fig. (2). Raman spectra of the BDD film.

The electrochemical windows for the BDD film, Pt and ACT electrodes are shown in Fig. (3). It showed that in contrast to the $\mathrm{Pt}$ and ACT electrodes, the BDD film electrode possesses the largest electrochemical window, which is wider than $3 \mathrm{~V}$ in our experiment. The wide electrochemical window is beneficial to the organic matter degradation. Therefore, the BDD film electrode is more effective than the other two electrodes in the electrooxidation process.

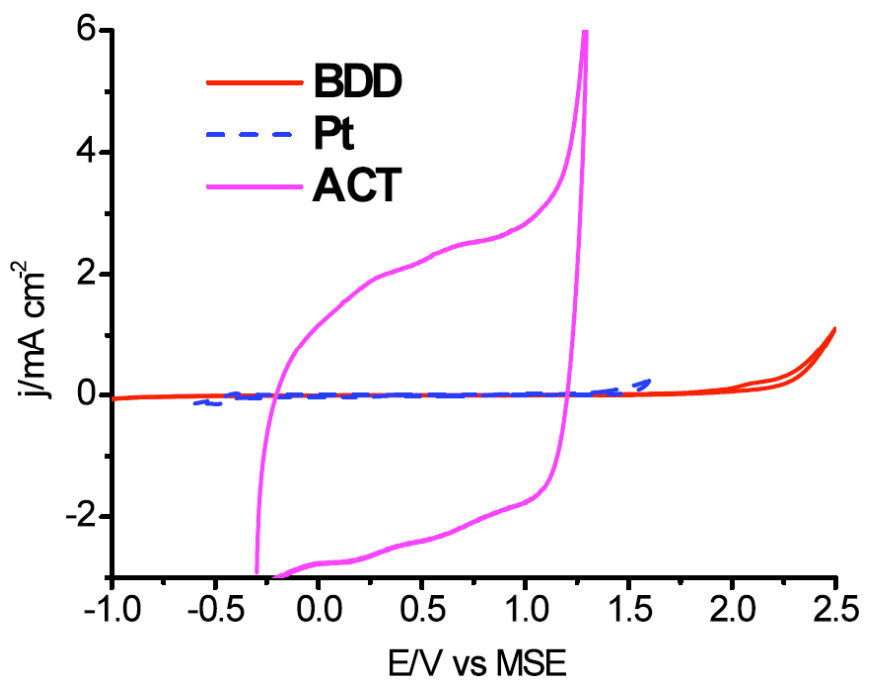

Fig. (3). The electrochemical windows for the BDD, Pt and ACT electrodes.

In order to investigate the effect of the chlorine atom number on the cyclic voltammetry in the benzene ring of the chlorophenols, $1 \mathrm{mM}$ 2-CP, 2,4-DCP, 2,4,6-TCP and PCP solutions are used as the electrolyte with the $\mathrm{pH} 2.2$.

Fig. (4a-d) are the cyclic voltammograms of CPs at different scan rates. The CVs of the 2-CP (Fig. 4a) and 

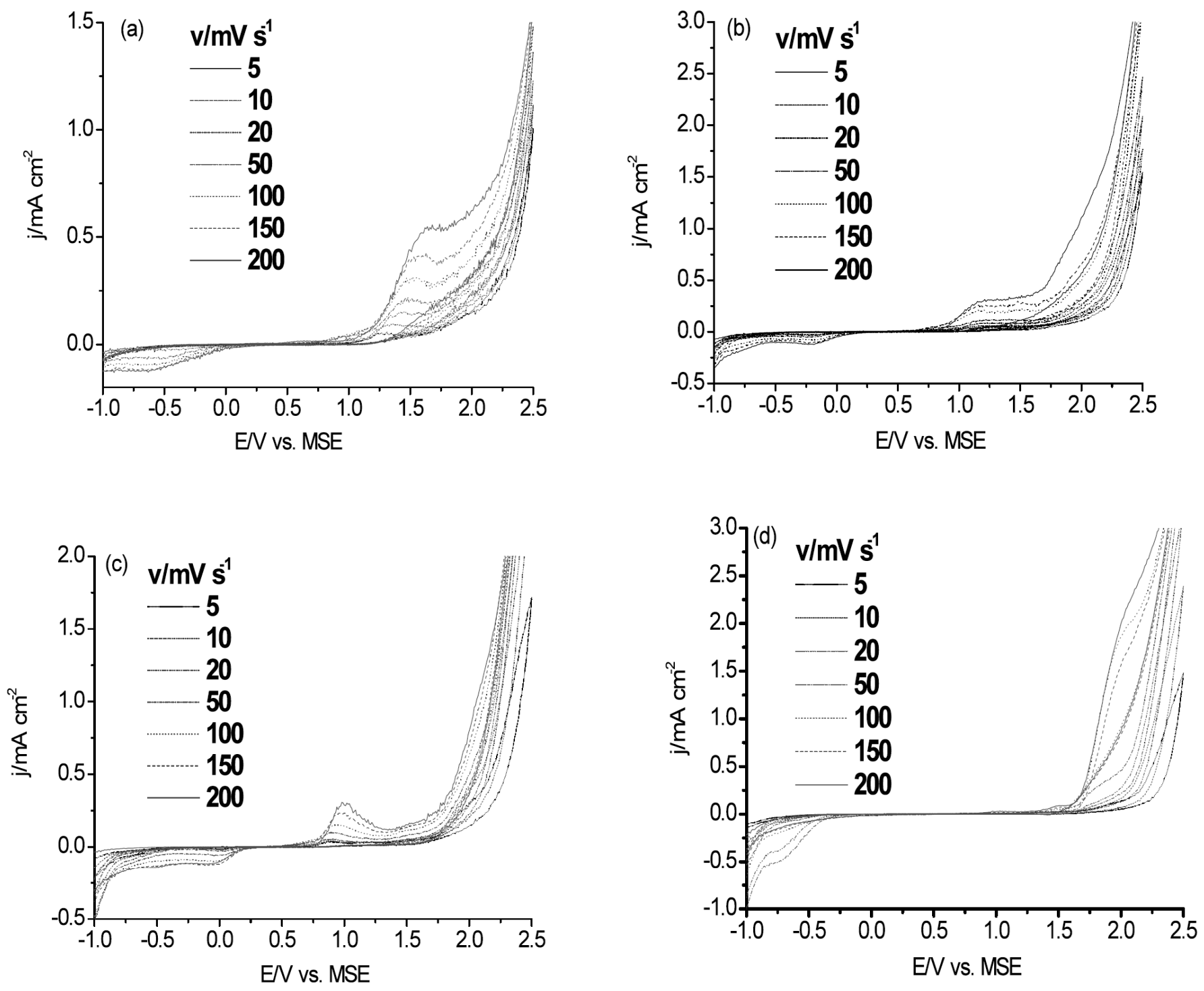

Fig. (4). The first cyclic voltammogram of different chlorophenol solutions with at different scan rates over the potential range of $-1 \mathrm{~V}$ to 2.5V (vs MSE), the scan rates are 5, 10, 20, 50, 100, 150, 200mV/s. (a): 2-CP; (b): 2,4-DCP; (c): 2,4,6-TCP; (d): PCP.

2,4,6-TCP (Fig. 4c) both have obvious anodic peaks, the peak value of the former amounts to about $0.310 \mathrm{~mA} \mathrm{~cm}^{-2}$ at the scan rate of $100 \mathrm{mV} / \mathrm{s}$, the one of the latter amounts to about $0.150 \mathrm{~mA} \mathrm{~cm} \mathrm{~cm}^{-2}$. In addition, the cathodic peaks of the cyclic voltammograms corresponding to the two chlorophenols are broad, which indicates the induction of an insoluble oxidation product. In the case of the peak potentials, the anodic peak potentials of the 2-CP and 2,4,6TCP at the scan rate of $100 \mathrm{mV} / \mathrm{s}$ are approximate $1.550 \mathrm{~V}$ and $0.950 \mathrm{~V}$ respectively. The cathodic peak potentials of the two chlorophenols are approximate $-0.580 \mathrm{~V}$ and $-0.010 \mathrm{~V}$ (vs MSE), respectively. Compared with the 2-CP and 2,4,6TCP, the cyclic voltammogram of the 2,4-DCP (Fig. 4b) has a broad anodic peak but an obvious cathodic peak. At the scan rate of $100 \mathrm{mV} / \mathrm{s}$, the anodic peak current is about $0.200 \mathrm{~mA} \mathrm{~cm}^{-2}$ with the peak potential of $1.17 \mathrm{~V}$ ( $v s \mathrm{MSE}$ ) and the cathodic peak current is about $-0.072 \mathrm{~mA} \mathrm{~cm}^{-2}$ with the peak potential of $-0.034 \mathrm{~V}$. The overpotential of the $2-\mathrm{CP}$ obtained in the experiment is slightly higher than the results given in the report [13]. We attribute this inconsistency to the different structure of the grown diamond film, because the grain size of our deposited diamond film is much larger than that reported by Muna (about 50-100nm) [13]. The larger diamond crystal has less grain boundary formed mainly by $\mathrm{sp} 2$ phase, which evidently impacts the overpotential of the electrode. In contrast to the three CPs, the cyclic voltammogram of the PCP (Fig. 4d) exhibits neither obvious anodic peak current nor cathodic peak current.

To further investigate the cyclic voltammograms of the chlorophenols, the plots of the peak current densities versus the square root of the scan rate and logarithm of peak current densities versus logarithm of the scan rate are drawn as Fig. $(\mathbf{5 a}, \mathbf{b})$, respectively. Some characteristic parameters of the cyclic voltammograms are calculated according to Figs. (4, 5). The results are listed in Table 1. The intervals of the anodic peak potential and the cathodic peak potential $(\Delta \mathrm{Ep})$ decrease as the $\mathrm{Cl}$ atom number in the benzene ring increases. It indicates that the irreversible reaction becomes less dramatic as the $\mathrm{Cl}$ atom number in the benzene ring increases. Moreover, because the $\Delta \mathrm{Ep}$ of all the three 
chlorophenols greatly exceed the $59 \mathrm{mV}$, which meets with the reversible reaction according to the Nernst equation, they all belong to the irreversible reaction. This is in accordance with the ratios of the reduction to the oxidation charge (Ipc/Ipa), which are between $0.3 \sim 0.5$ to all the three chlorophenols and decrease with the increase of the $\mathrm{Cl}$ atom number.

On the other hand, all the anodic and cathodic peak currents are proportional to the square root of the scan rate. It indicates that the reaction is controlled by mass transport. The slopes of the lines for anodic peaks in Fig 5 (a) are $0.039,0.022$ and 0.020 corresponding to 2-CP, 2,4-DCP and 2,4,6-TCP, respectively. So the slopes of the lines decrease as the $\mathrm{Cl}$ atom number in the benzene ring increases. In Fig 5 (b), the logarithm of anodic peaks current densities is also proportional to logarithm of the scan rate. The slopes of the lines are almost the same (all in the range of $0.5 \sim 0.6$ ). It follows that the activity of the electrode is not altered as the chlorophenols change in the process of the cyclic voltammetry [1].
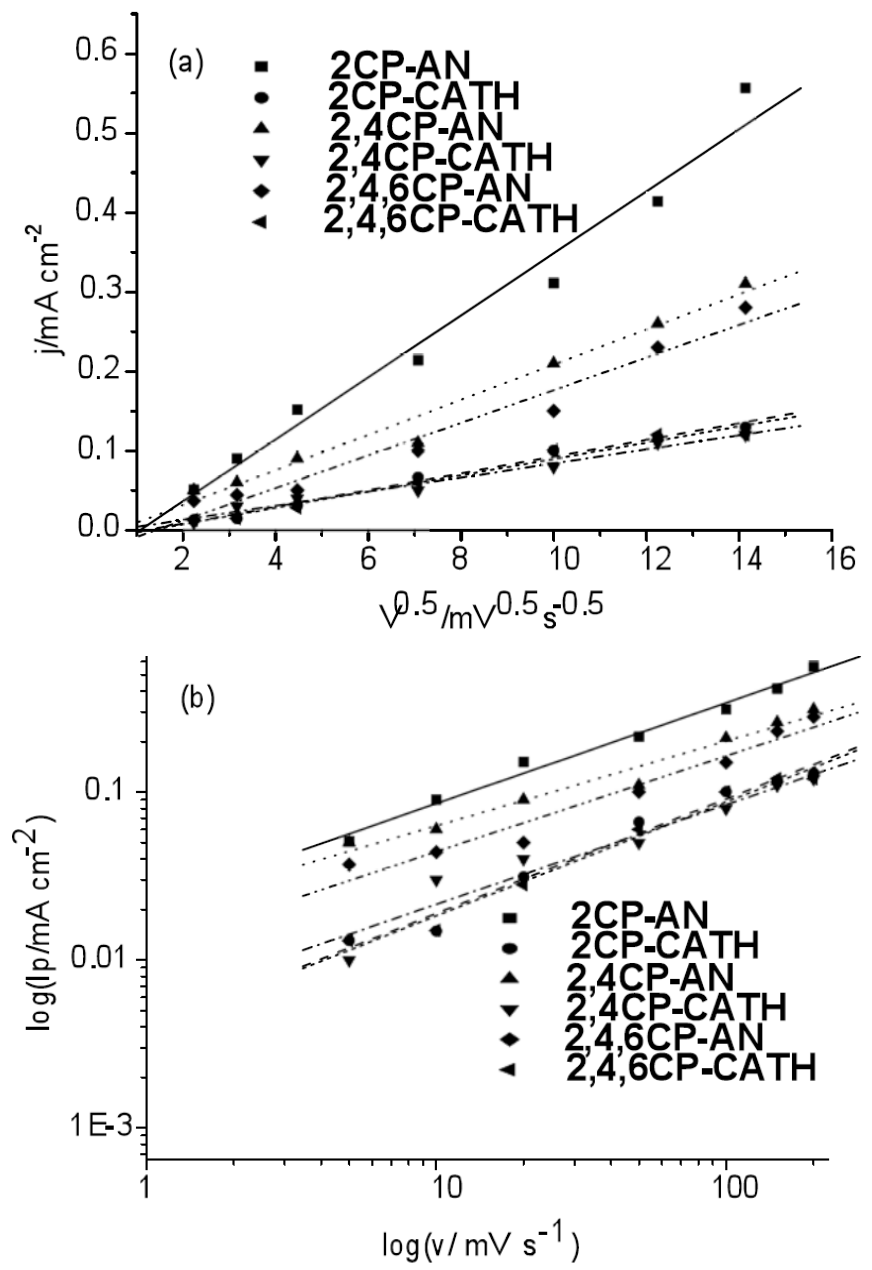

Fig. (5). (a) Plot of the anodic and cathodic peak current densities versus the square root of the scan rate; (b): Plot of logarithm of peak current densities versus logarithm of the scan rate. $\mathbf{m}$ : the anodic peak of 2-CP; $\bullet$ : the cathodic peak of 2-CP; $\boldsymbol{\Delta}$ : the anodic peak of 2,4-DCP; $\boldsymbol{\nabla}$ : the cathodic peak of 2,4-DCP; $:$ the anodic peak of 2,4,6-TCP; 4 : the cathodic peak of 2,4,6-TCP.
Table 1. Cyclic Voltammetric Parameters of the Anodic and Cathodic Peak for Different $\mathrm{CP}$ in the Solution of $0.5 \mathrm{M} \mathrm{Na}_{2} \mathrm{SO}_{4}+10 \mathrm{mM} \mathrm{H}_{2} \mathrm{SO}_{4}(\mathrm{pH}=2.2)+1 \mathrm{mM} \mathrm{CP}$

\begin{tabular}{|c|c|c|c|c|}
\hline $\mathbf{C P}$ & $\partial \log I_{p}^{a n} / \partial \log v$ & $\partial I_{p}^{a n} / \partial \sqrt{v}$ & $\boldsymbol{I p c} / \mathbf{I p a}$ & $\Delta \boldsymbol{E p}[\mathbf{V}]$ \\
\hline \hline $2-\mathrm{CP}$ & 0.60 & 0.039 & 0.31 & 2.13 \\
\hline $2,4-\mathrm{DCP}$ & 0.50 & 0.022 & 0.36 & 1.20 \\
\hline $2,4,6-\mathrm{TCP}$ & 0.57 & 0.020 & 0.43 & 0.96 \\
\hline PCP & - & - & - & - \\
\hline
\end{tabular}

Noted the cyclic voltammogram of the PCP solution, it is very different from the cyclic voltammograms of the other three chlorophenols. There is no clear peak at both the anodic scans and cathodic scans, but they exhibit shoulders when the scan rate exceeds $100 \mathrm{mV} / \mathrm{s}$. It reflects that the reaction is complex. Moreover, as the scanning number at the scan rate of $200 \mathrm{mV} / \mathrm{s}$ increases, the shoulders on the curves rapidly diminish and then disappear at the fifth scanning. It is probably due to the heavy fouling of the electrode (Fig. 6).

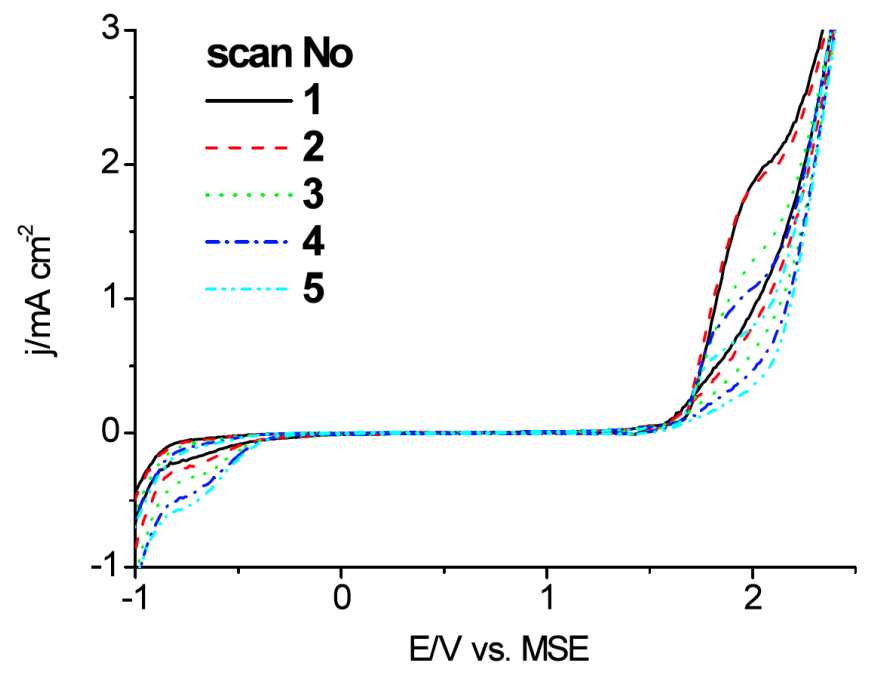

Fig. (6). The cyclic voltammograms of the five numbers of scanning in PCP solution at the scan rate of $200 \mathrm{mV} / \mathrm{s}$.

According to the cyclic voltammograms of the CPs, the electro-oxidation begins with single electron transfer. Now, we take the 2-CP, 2,4-DCP and PCP as the examples to present their electro-oxidation mechanisms.

\section{(a) Anodic Oxidation Process of the 2-CP}

$\mathrm{I}$ : Oxygenized into phenoxy radical $\left(\mathrm{C}_{6} \mathrm{H}_{4} \mathrm{ClO}^{*}\right)$ and $\mathrm{C}_{6} \mathrm{H}_{4} \mathrm{ClO}^{+}$

$$
\mathrm{C}_{6} \mathrm{H}_{4} \mathrm{ClOH} \rightarrow \mathrm{C}_{6} \mathrm{H}_{4} \mathrm{ClO}^{*}+\mathrm{H}^{+}+\mathrm{e}^{-} \rightarrow \mathrm{C}_{6} \mathrm{H}_{4} \mathrm{ClO}^{+}
$$

II: Reaction of the $\mathrm{C}_{6} \mathrm{H}_{4} \mathrm{ClO}^{+}$and $\mathrm{H}_{2} \mathrm{O}$ into 1,4benzoquinone

$$
\mathrm{C}_{6} \mathrm{H}_{4} \mathrm{ClO}^{+}+\mathrm{H}_{2} \mathrm{O} \rightarrow \mathrm{OC}_{6} \mathrm{H}_{4} \mathrm{ClOH}+\mathrm{H}^{+} \rightarrow \mathrm{OC}_{6} \mathrm{H}_{4} \mathrm{ClO}
$$

The coupling takes place by a parallel reaction path for the $\mathrm{C}_{6} \mathrm{H}_{4} \mathrm{ClO}^{*}$ and $\mathrm{C}_{6} \mathrm{H}_{4} \mathrm{ClO}^{+}$, and the polymer is generated. 


\section{(b) Anodic Oxidation Process of the 2,4-DCP}

I: Forming phenoxy radical

$$
\mathrm{C}_{6} \mathrm{H}_{3} \mathrm{Cl}_{2} \mathrm{OH} \rightarrow \mathrm{C}_{6} \mathrm{H}_{3} \mathrm{Cl}_{2} \mathrm{O}^{*}+\mathrm{H}^{+}+\mathrm{e}^{-}
$$

II: According to the above results, it can be induced that the phenoxy radical could react at least in two ways: one is that the radical initiates a polymerization; the other is that the radical is oxidized to a quinone-like structure with loss of three electrons.

\section{(c) Anodic Oxidation Process of the PCP}

$$
\begin{aligned}
& \text { I: Forming } \mathrm{C}_{6} \mathrm{Cl}_{5} \mathrm{O}^{*} \\
& \mathrm{C}_{6} \mathrm{Cl}_{5} \mathrm{O}^{-} \rightarrow \mathrm{C}_{6} \mathrm{Cl}_{5} \mathrm{O}^{*}+\mathrm{e}^{-}
\end{aligned}
$$

The following reaction paths probably is

II: Coupling between the $\mathrm{C}_{6} \mathrm{Cl}_{5} \mathrm{O}^{*}$

$2 \mathrm{C}_{6} \mathrm{Cl}_{5} \mathrm{O}^{*} \rightarrow \mathrm{C}_{6} \mathrm{Cl}_{5} \mathrm{O} \mathrm{C}_{6} \mathrm{Cl}_{5} \mathrm{O}$

III: Coupling between the $\mathrm{C}_{6} \mathrm{Cl}_{5} \mathrm{O}^{*}$ and $\mathrm{C}_{6} \mathrm{Cl}_{5} \mathrm{O}^{-}$

$$
\mathrm{C}_{6} \mathrm{Cl}_{5} \mathrm{O}^{*}+\mathrm{C}_{6} \mathrm{Cl}_{5} \mathrm{O}^{-} \rightarrow\left[\mathrm{C}_{6} \mathrm{Cl}_{5} \mathrm{OC}_{6} \mathrm{Cl}_{5} \mathrm{O}\right]^{*}
$$

\section{Oxidizing}

$$
\left[\mathrm{C}_{6} \mathrm{Cl}_{5} \mathrm{OC}_{6} \mathrm{Cl}_{5} \mathrm{O}\right]^{*-} \rightarrow \mathrm{C}_{6} \mathrm{Cl}_{5} \mathrm{O} \mathrm{C} \mathrm{Cl}_{6} \mathrm{O}+\mathrm{e}^{-}
$$

\section{De-Protonizing}

$$
\mathrm{C}_{6} \mathrm{Cl}_{5} \mathrm{O}^{*}+\left[\mathrm{C}_{6} \mathrm{Cl}_{5} \mathrm{OC}_{6} \mathrm{Cl}_{5} \mathrm{O}\right]^{*-} \rightarrow \mathrm{C}_{6} \mathrm{Cl}_{5} \mathrm{O} \mathrm{C}_{6} \mathrm{Cl}_{5} \mathrm{O}+\mathrm{C}_{6} \mathrm{Cl}_{5} \mathrm{O}^{-}
$$

\section{De-Chlorinating}

$$
\begin{aligned}
& {\left[\mathrm{C}_{6} \mathrm{Cl}_{5} \mathrm{OC}_{6} \mathrm{Cl}_{5} \mathrm{O}\right]^{*-} \rightarrow\left[\mathrm{C}_{6} \mathrm{Cl}_{5} \mathrm{OC}_{6} \mathrm{Cl}_{4} \mathrm{O}\right]^{*}+\mathrm{Cl}^{-}} \\
& \text {IV: Oxygenization of the } \mathrm{C}_{6} \mathrm{Cl}_{5} \mathrm{O}^{*} \text { into } \mathrm{C}_{6} \mathrm{Cl}_{5} \mathrm{O}^{+} \\
& \mathrm{C}_{6} \mathrm{Cl}_{5} \mathrm{O}^{*} \rightarrow \mathrm{C}_{6} \mathrm{Cl}_{5} \mathrm{O}^{+}+\mathrm{e}^{-}
\end{aligned}
$$

\section{Coupling of the Positive Ion and the Negative Ion}

$$
\mathrm{C}_{6} \mathrm{Cl}_{5} \mathrm{O}^{+}+\mathrm{C}_{6} \mathrm{Cl}_{5} \mathrm{O}^{-} \rightarrow \mathrm{C}_{6} \mathrm{Cl}_{5} \mathrm{O} \mathrm{C} \mathrm{C}_{6} \mathrm{Cl}_{5} \mathrm{O}
$$

Forming the Quinone by the Coupling of the Ions and the Solvent

$$
\begin{aligned}
& \mathrm{C}_{6} \mathrm{Cl}_{5} \mathrm{O}^{+}+\mathrm{H}_{2} \mathrm{O} \rightarrow \mathrm{OC}_{6} \mathrm{Cl}_{5} \mathrm{OH}+\mathrm{H}^{+} \\
& \mathrm{OC}_{6} \mathrm{Cl}_{5} \mathrm{OH} \rightarrow \mathrm{OC}_{6} \mathrm{Cl}_{4} \mathrm{O}+\mathrm{H}^{+}+\mathrm{Cl}^{-}
\end{aligned}
$$

In contrast to the 2-CP and 2,4-CP, the reaction mechanism for the PCP is more complex. This is consistent with its cyclic voltammograms, which has no obvious peak, but exhibits a shoulder.

\section{CONCLUSIONS}

The characteristic of the cyclic voltammograms changes with the different number of chlorine atoms. For the 2-CP, 2,4-DCP and 2,4,6-TCP, the reactions are irreversible and under diffusion control, and the chlorine atoms in the benzene ring influence the degree of the irreversibility. As the number of the chlorine atoms decreases, the reaction becomes more irreversible. The activity of the boron-doped diamond electrode does not depend on the number of the chlorine atoms of the chlorophenols. In the case of the PCP, heavy fouling of the electrode surface takes place in the experiment. In addition, the possible electro-oxidation mechanisms are presented.

\section{ACKNOWLEDGEMENTS}

This project was supported by the National Nature Science Foundation of China under Grant No. 51075004 and the Young Key Project of North China University of Technology.

\section{REFERENCES}

[1] Burrows HD, Ernestova LS, Kemp TJ, Skurlatov YI, Purmal AP, Yermakov AN. Kinetics and mechanism of photodegradation of chlorophenols. Prog React Kinet 1998; 23: 145-207.

[2] Budavari S, O'Neil MJ, Smith A, Heckelman PE, Eds. The Merck index: an encyclopaedia of chemicals, drugs and biologicals. 11th ed. New Jersey: Merck; 1989.

[3] Zhang H, Sung MH, Huang CP. Mathematical model of in-situ ozonation for the remediation of 2-chlorophenol contaminated soil. Chin J Chem Eng 2003; 5: 555-8.

[4] Kookana RS, Rogers SL. Effects of pulp mill effluent disposal on soil. Rev Environ Contam Toxicol 1995; 142: 13-64.

[5] Xue XH, Wang DH. Catalytic wet air oxidation of o-chlorophenol in wastewater. Chin J Chem Eng 2003; 3: 352-4.

[6] Ureta-Zañartu MS, Bustos P, Berrios C, Diez MC, Mora ML, Gutierrez C. Electrooxidation of 2,4-dichlorophenol and other polychlorinated phenols at a glassy carbon electrode. Electrochim Acta 2002; 47: 2399-406.

[7] Montilla F, Machaud PA, Morallon E, Vazquez JL, Comninellis C. Electrochemical oxidation of benzoic acid at boron-doped diamond electrodes. Electrochim Acta 2002; 47: 3509-13.

[8] Gattrell M, Kirk DW. The electrochemical oxidation of phenol at a glassy carbon electrode. Can J Chem Eng 1990; 68: 997-1003.

[9] Iniesta J, Michaud PA, Panizza M, Cerisola G, Aldaz A, Comninellis C. Electrochemical oxidation of phenol at borondoped diamond electrode. Electrochim Acta 2001; 46: 3573-8.

[10] Cañizares P, Garcia-Gómez J, Sáez C, Rodrigo MA. Electrochemical oxidation of several chlorophenols on diamond electrodes: I. Reaction mechanism. J Appl Electrochem 2003; 33: 917-27.

[11] Stradinis J, Hasanli B. Anodic voltammetry of phenol and benzenethiol derivatives: Part 1. Influence of $\mathrm{pH}$ on electrooxidation potentials of substituted phenols and evaluation of $\mathrm{pKa}$ from anodic voltammetry data. J Electroanal Chem 1993; 353: 5769.

[12] Gonon P, Gheeraert E, Deneuville S Fontaine F, Abello L, Lucazeau G. Characterization of heavily B-doped polycrystalline diamond films using Raman spectroscopy and electron spin resonance. J Appl Phys 1995; 78: 7059-62.

[13] Muna GW, Tashewa N, Swain GM. Electro-oxidation and amperometric detection of chlorinated phenols at boron-doped diamond electrodes: a comparison of microcrystalline and nanocrystalline thin films. Environ Sci Technol 2004; 38: 3674-82. 